\title{
Research on Probability Mean-Lower Semivariance-Entropy Portfolio Model with Background Risk
}

\author{
Qi Wu, ${ }^{1}$ Yuelin Gao $\mathbb{D}^{1,2}$ and Ying Sun ${ }^{10}{ }^{2}$ \\ ${ }^{1}$ Ningxia Province Key Laboratory of Intelligent Information and Data Processing, North Minzu University, \\ Yinchuan 750021, China \\ ${ }^{2}$ Ningxia Cooperative Innovation Center of Scientific Computing and Intelligent Information Processing, \\ North Minzu University, Yinchuan 750021, China \\ Correspondence should be addressed to Yuelin Gao; gaoyuelin@263.net
}

Received 29 March 2020; Accepted 5 June 2020; Published 17 July 2020

Guest Editor: Zaoli Yang

Copyright $\odot 2020$ Qi Wu et al. This is an open access article distributed under the Creative Commons Attribution License, which permits unrestricted use, distribution, and reproduction in any medium, provided the original work is properly cited.

\begin{abstract}
In the financial market, investors must deal with uncertain risk, and they also face background risk and many uncertain factors caused by their own characteristics. Considering the fuzzy nature of these factors as well as investors' risk preferences, transaction costs, and so on, in order to reduce investment risk, an improved probability entropy measure is introduced, and a probability mean-lower semivariance-entropy model with different risk attitudes is established by using fuzzy sets and probability theory. To solve the portfolio model, an improved differential evolution algorithm is proposed and a numerical example is given. The numerical results show that the proposed algorithm is effective and that the model can disperse the financial risk to a certain extent and reasonably solve the portfolio problem under many different conditions.
\end{abstract}

\section{Introduction}

The portfolio problem studies how to reasonably distribute the wealth in the hands of investors to different assets in order to realize the rapid growth of wealth and control investment risk. Markowitz [1] put forward the classical mean-variance $(\mathrm{m}-\mathrm{v})$ model in 1952 , which provided the theoretical basis for the portfolio problem and introduced the era of quantitative analysis. The basic idea is to measure returns via the expected return of an asset, to measure the risk via the variance of the return of an asset, to minimize the risk when the expected return of a portfolio is certain, or to maximize the expected return of a portfolio when the risk taken by the investor is certain. Many researchers, such as $\mathrm{Yu}$ and Lee [2] and Shen et al. [3], have made many extensions to this. The models mentioned above measure the risk using the variance. Because the distribution of asset returns is asymmetrical, using the variance to measure risk may sacrifice too much of the expected returns in the process of eliminating the extreme low or high returns. To express or measure the real investment risk in financial market more accurately, scholars have proposed new risk measurement indicators that can be used instead of the variance. For example, Petters and Dong [4] introduce the capital asset pricing model (CAPM), the linear factor model and the concepts of the value at risk, and the conditional value at risk and related risk measurements. Kang and $\mathrm{Li}$ [5] propose a unified framework to solve the distributed robust average risk optimization problem, which uses the variance, VaR, and CVaR as the three risk measures. Ma et al. [6] employ the Lagrange dual method and the BSDE theory to tackle a continuous-time $\mathrm{m}-\mathrm{v}$ asset-liability management problem. To explore the multiple heterogeneous relationships among membership functions and criteria, a novel decision algorithm is based on q-ROF set in literature [7] to deal with these using interactive operators and Maclaurin symmetric mean (MSM) operators.

Financial market risk is considered to be uncertain, and Shape [8] is of the view that the uncertainty in financial markets cannot be predicted based on certainty. Risk, uncertainty, and randomness are equal to each other. Probability theory is used to describe random uncertainty. Qin [9] 
first gives a measure of the variance of portfolio returns, verifies it based on uncertainty theory, and then introduces the corresponding mean-variance model. Zhang and Chen [10] study the mean-variance portfolio selection problem with system switching under the constraint of banning short selling. However, a financial market is an extremely complex system, and the influence of human factors on investors' decision-making in the investment process should not be underestimated. Investors will make different investment decisions under the influence of social factors, psychological factors, subjective will, and personal experience. In the light of these factors, in 1970, Bellman and Zadeh [11] put forward the theory of fuzzy decision-making. Tiryaki and Fang et al. [12] describe the investor's point of view with fuzzy sets; construct two fuzzy Black-Litterman models with the fuzzy view and the fuzzy random view, respectively; redefine the expected return and uncertainty matrix of view; and use fuzzy methods to appropriately represent the view. It is shown that the fuzzy method can better represent the information in the view and more accurately measure the uncertainty. Tsaur [13] develops a fuzzy portfolio model that focuses on different investor risk attitudes and thus enables fuzzy portfolio selection for investors with different risk attitudes. Yang et al. [14] proposed a deep-learning model, and the sentiment dictionary is used to calculate sentiment orientation, which is represented by the q-rung orthopair fuzzy set. Due to the uncertainty effects of COVID-19 and limits of human cognition, Yang et al. [15] proposed a decision support algorithm based on the novel concept of the spherical normal fuzzy ( $\mathrm{SpNoF}$ ) set.

In the investment process, people face not only financial risks but also background risks, including those related to labour income, proprietary income, real estate investment, unexpected expenses caused by health problems, health insurance, and so on. Different investors have different attitudes towards risk, and extremely rational investors are absolutely risk averse. How to diversify investment to reduce risk has become a hot issue that has been studied by researchers. As early as 1952, Markowitz put forward a view of the "Don't put your eggs in the same basket," which fully illustrates the importance of decentralized investment. At present, some scholars have used proportional entropy as a combined measure for decentralized portfolios. Huang [16] considers the credibility applying the mean-variance model and mean-semivariance model to proportional entropy fuzzy portfolios, as well as the clear form of the corresponding model. Lassance and Vrins [17] accurately quantify the uncertainty embedded in a distribution using a target function that depends on the R'enyi entropy index and considers the high-order moments. The portfolio generates a number of minimum variance combinations that are superior to the prior settings by minimizing the R'enyi entropy in terms of the risk-working capital trade closure. Fang et al. [18] consider the degree of diversification of a portfolio. Lee et al. [19] consider the limited control of total funds, such as the total, risk, and liquidity, to achieve a distributed strategic asset allocation with global constraints. Li et al. [20] discuss fuzzy multiobjective dynamic portfolio optimization for time-inconsistent investors, establish a model to simultaneously maximize the cumulative combined objective function and minimize the cumulative portfolio variance, and design and propose a multiobjective dynamic evolutionary algorithm as a possible solution to the proposed model. A novel approach based on the genetic algorithm (GA) for feature selection and parameter optimization of support vector machine (SVM) is proposed in literature [21]. Yang and Chang [22] proposed the interval-valued Pythagorean normal fuzzy (IVPNF) sets by introducing the NFN into IVPF environment.

The structure of the remainder of this paper is as follows. In Section 2, the relevant concepts are given, including the membership function of the trapezoid fuzzy number, the mean probability value, the lower semivariance of the probability, and so on. In Section 3, the establishment process of the probability mean-lower semivariance-entropy model is given. In Section 4, an improved differential evolution algorithm is designed to solve the model. Section 5 uses Chinese stock market data to conduct the empirical analysis, including the investors with different risk attitudes. It contains the two aspects of background risk and transaction costs and discusses the portfolio problem of how risk attitudes and background risk affect investors' decisionmaking. Finally, some conclusions are given in Section 6.

\section{Preliminaries}

Definition 1. Li [23] defined a fuzzy set as $\widetilde{A} \in F(U)$, for any $\gamma \in[0,1]$. Then, fuzzy set $\widetilde{A}$ with a $\gamma$-level set $[\widetilde{A}]^{\gamma}$ is defined as

$$
[\tilde{A}]^{\gamma}=\left\{x \mid x \in U, \mu_{\tilde{A}}(x) \geq \gamma\right\}=[\underline{a}(\gamma), \bar{a}(\gamma)],
$$

where $\gamma$ is the confidence level. $\underline{a}(\gamma)$ and $\bar{a}(\gamma)$ are denoted as the left and right endpoints of the $\gamma$ level set, respectively.

Definition 2. Li [23] defined $\widetilde{A}=(a, b, \alpha, \beta)$ is a trapezoidal fuzzy number. Then, the membership function of the trapezoidal fuzzy number with the risk attitude is defined as

$$
\mu \sim \tau_{A}(x)= \begin{cases}1-\left(\frac{a-x}{\alpha}\right)^{k}, & a-\alpha \leq x \leq a, \\ 1, & a \leq x \leq b, \\ 1-\left(\frac{x-b}{\beta}\right)^{k}, & b \leq x \leq b+\beta, \\ 0, & \text { otherwise, }\end{cases}
$$

where $k$ is a real number greater than 0 , which is the fitness of the risk attitude. The $[a, b]$ known as the trapezoidal fuzzy number of peak area, $\alpha$ and $\beta$, respectively, is called $\widetilde{A}$ width of left and right, as shown in Figure 1. By finding the derivative of the above membership function, we can know that the smaller the $k$ is, the more averse the investors are to risk.

In view of the above formula of (2) of the trapezoidal fuzzy number with the risk attitude and the definition of 


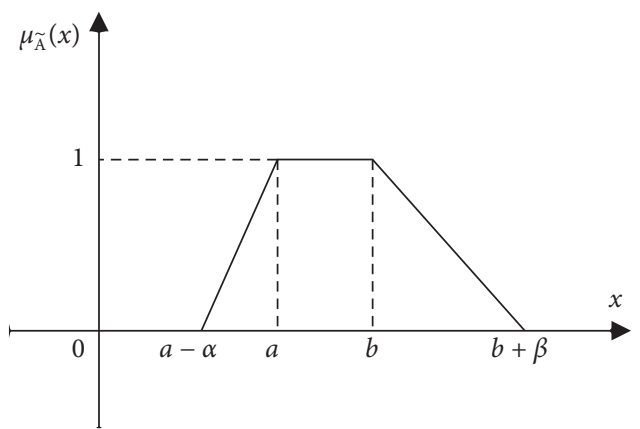

Figure 1: Membership function of trapezoidal fuzzy number $\widetilde{A}$.

$\gamma$-level set, the $\gamma$-level set [23] of $\tilde{A}$ can be obtained as follows: $[\widetilde{A}]^{\gamma}=[\underline{a}, \bar{a}]=\left[a-\alpha(1-\gamma)^{1 / k}, b+\beta(1-\gamma)^{1 / k}\right]$.

The upper and lower mean probabilities of trapezoidal fuzzy number $\widetilde{A}$ with the risk attitude [23] are, respectively, denoted as

$$
M^{+}(\widetilde{A})=2 \int_{0}^{1} \gamma\left[b+\beta(1-\gamma)^{1 / k}\right] \mathrm{d} \gamma=b+\frac{2 k^{2} \beta}{(2 k+1)(k+1)},
$$

$$
M^{-}(\tilde{A})=2 \int_{0}^{1} \gamma\left[a-\alpha(1-\gamma)^{1 / k}\right] \mathrm{d} \gamma=a-\frac{2 k^{2} \alpha}{(2 k+1)(k+1)} .
$$

Via formulas (3) and (4), the mean value of the clear probability of trapezoidal fuzzy number $\widetilde{A}$ with the risk attitude [23] is denoted as

$$
M(\widetilde{A})=\frac{1}{2}\left(M^{-}(\widetilde{A})+M^{+}(\widetilde{A})\right)=\frac{a+b}{2}+\frac{k^{2}(\beta-\alpha)}{(2 k+1)(k+1)} .
$$

The upper and lower semivariances of the probability of trapezoidal fuzzy number $\widetilde{A}$ with the risk attitude are as follows:

$$
\begin{aligned}
& \operatorname{Var}^{+}(\widetilde{A})=2 \int_{0}^{1} \gamma(M(\widetilde{A})-\bar{a}(\gamma))^{2} \mathrm{~d} \gamma, \\
& \operatorname{Var}^{-}(\widetilde{A})=2 \int_{0}^{1} \gamma(M(\widetilde{A})-\underline{a}(\gamma))^{2} \mathrm{~d} \gamma .
\end{aligned}
$$

From the above formulas (6) and (7), the clear variance of the probability of trapezoidal fuzzy number $\widetilde{A}$ with the risk attitude [23] is denoted as

$$
\begin{aligned}
\operatorname{Var}(\widetilde{A}) & =\frac{1}{2} \int_{0}^{1} \gamma[\bar{a}(\gamma)-\underline{a}(\gamma)]^{2} \mathrm{~d} \gamma \\
& =\frac{1}{2} \int_{0}^{1} \gamma\left[b+\beta(1-\gamma)^{1 / k}-\left(a-\alpha(1-\gamma)^{1 / k}\right)\right]^{2} \mathrm{~d} \gamma \\
& =\frac{(b-a)^{2}}{4}+\frac{k^{2}(b-a)(\alpha+\beta)}{(2 k+1)(k+1)}+\frac{k^{2}(\alpha+\beta)^{2}}{4(k+1)(k+2)} .
\end{aligned}
$$

\section{Establishment of Model}

The securities market is an extremely complex system. The returns and risk of securities are uncertain, and especially the influence of human factors on investment decisions cannot be ignored. In many cases, the returns and risks of securities can only be described in some vague languages, such as low risk and low return and high risk and high return. This makes investors make investment decisions in vague environments. For the convenience of the explanation, first of all, the relevant symbols involved in this paper are given as follows:

$\widetilde{r}_{i}=\left(a_{i}, b_{i}, \alpha_{i}, \beta_{i}\right)$ represents the rate of return on financial risk asset $i$

$\widetilde{r}_{b}=\left(a_{b}, b_{b}, \alpha_{b}, \beta_{b}\right)$ represents the rate of return on background risk asset $b$

$c_{i}$ represents the unit transaction cost of asset $i$

$X=\left(x_{1}, x_{2}, \ldots, x_{n}\right)$ represents the asset portfolio

$x_{i}$ represents the investment proportion of risk asset $i$ $k$ represents the fitness value of the risk attitude, where $k$ is a real number greater than 0

$\operatorname{Cov}\left(\widetilde{r}_{i}, \widetilde{r}_{j}\right)$ represents the possible covariance between asset $i$ and asset $j$

$\operatorname{Cov}\left(\widetilde{r}_{i}, \widetilde{r}_{b}\right)$ represents the possible covariance between financial risk asset $i$ and background risk asset $b$

$S(x)$ represents the likelihood entropy

Suppose there are $n$ kinds of assets in the market, and the rate of return $\tilde{r}_{i}$ of each asset is a trapezoidal fuzzy variable $\tilde{r}_{i}=\left(a_{i}, b_{i}, \alpha_{i}, \beta_{i}\right), i=1,2, \ldots, n$ with the risk attitude. The corresponding $\gamma$ level set is denoted as $\left[\widetilde{r}_{i}\right]=\left[r_{i 1}(\gamma), r_{i 2}(\gamma)\right]=\left[a_{i}-\alpha_{i}(1-\gamma)^{1 / k}, b_{i}+\beta_{i}(1-\gamma)^{1 / k}\right]$.

The membership function of financial risk assets with risk attitude [23] is as follows:

$$
\mu_{r_{i}}(x)= \begin{cases}1-\left(\frac{a_{i}-x}{\alpha_{i}}\right)^{k}, & a_{i}-\alpha_{i} \leq x \leq a_{i}, \\ 1, & a_{i} \leq x \leq b_{i} \\ 1-\left(\frac{x-b_{i}}{\beta_{i}}\right)^{k}, & b_{i} \leq x \leq b_{i}+\beta_{i}, \\ 0, & \text { otherwise. }\end{cases}
$$

It is assumed that the return of the asset with background risk $\widetilde{r}_{b}$ is also a trapezoidal fuzzy variable $\widetilde{r}_{b}=\left(a_{b}, b_{b}, \alpha_{b}, \beta_{b}\right)$ with the risk attitude and the corresponding $\gamma$ level set is denoted as $\left[\widetilde{r}_{b}\right]=\left[r_{b 1}(\gamma), \quad r_{b 2}(\gamma)\right]=\left[a_{b}-\alpha_{b}(1-\gamma)^{1 / k}\right.$, $\left.b_{b}+\beta_{b}(1-\gamma)^{1 / k}\right]$. The membership function [18] of the asset with background risk is as follows: 


$$
\mu_{r_{b}}(x)= \begin{cases}1-\left(\frac{a_{b}-x}{\alpha_{b}}\right)^{k}, & a_{b}-\alpha_{b} \leq x \leq a_{b}, \\ 1, & a_{b} \leq x \leq b_{b}, \\ 1-\left(\frac{x-b_{b}}{\beta_{b}}\right)^{k}, & b_{b} \leq x \leq b_{b}+\beta_{b}, \\ 0, & \text { otherwise. }\end{cases}
$$

Suppose the investment strategy is self-financing; that is, no new funds are injected into the portfolio adjustment process. For the transaction cost function, we use the commonly used $V$-type function to represent it. Therefore, the total transaction cost of the portfolio is expressed as

$$
C=\sum_{i=1}^{n} c_{i}\left|x_{i}-x_{i}^{0}\right| .
$$

Thus, the equation containing background risks and transaction costs is expressed as follows:

$$
\widetilde{R}=\sum_{i=1}^{n} \widetilde{r}_{i} x_{i}+\widetilde{r}_{b}-C .
$$

Because the linear combination of the trapezoidal fuzzy numbers is a trapezoidal fuzzy number, $\sum_{i=1}^{n} \widetilde{r}_{i} x_{i}+\widetilde{r}_{b}=$ $\left(\sum_{i=1}^{n} x_{i} a_{i}+a_{b}, \sum_{i=1}^{n} x_{i} b_{i}+b_{b}, \sum_{i=1}^{n} x_{i} \alpha_{i}+\alpha_{b}, \sum_{i=1}^{n} x_{i} \beta_{i}+\beta_{b}\right)$.

Via formulas (3)-(5), the mean value of the clear probability of trapezoidal fuzzy number $\widetilde{R}$ with the risk attitude, background risk, and transaction cost is denoted as

$$
\begin{aligned}
M(\widetilde{R})= & M\left(\sum_{i=1}^{n} \widetilde{r}_{i} x_{i}+\widetilde{r}_{b}-C\right) \\
= & \sum_{i=1}^{n} x_{i} M\left(\widetilde{r}_{i}\right)+M\left(\widetilde{r}_{b}\right)-c_{i}\left|x_{i}-x_{i}^{0}\right| \\
= & \sum_{i=1}^{n} x_{i}\left(\frac{a_{i}+b_{i}}{2}+\frac{k^{2}\left(\beta_{i}-\alpha_{i}\right)}{(2 k+1)(k+1)}\right)+\frac{a_{b}+b_{b}}{2} \\
& +\frac{k^{2}\left(\beta_{b}-\alpha_{b}\right)}{(2 k+1)(k+1)}-c_{i}\left|x_{i}-x_{i}^{0}\right| .
\end{aligned}
$$

From formula (7), the lower semivariance of the clear probability of the trapezoid fuzzy number $\widetilde{R}$ is expressed as

$$
\begin{aligned}
& \operatorname{Var}^{-}(\widetilde{R})=\operatorname{Var}^{-}\left(\sum_{i=1}^{n} \widetilde{r}_{i} x_{i}+\widetilde{r}_{b}-C\right) \\
& =\sum_{i=1}^{n} x_{i}^{2} \operatorname{Var}^{-}\left(\widetilde{r}_{i}\right)+2 \sum_{i<j=1}^{n} x_{i} x_{j} \operatorname{Cov}^{-}\left(\widetilde{r}_{i}, \widetilde{r}_{j}\right)+\operatorname{Var}^{-}\left(\widetilde{r}_{b}\right)+2 \sum_{i=1}^{n} x_{i} \operatorname{Cov}^{-}\left(\widetilde{r}_{i}, \widetilde{r}_{b}\right) \\
& =\sum_{i=1}^{n} x_{i}^{2}\left\{\frac{\left(b_{i}-a_{i}\right)^{2}}{4}+\frac{k^{2} \alpha_{i}^{2}}{(k+1)(k+2)}+\frac{k^{2}\left(b_{i}-a_{i}\right)\left(\alpha_{i}+\beta_{i}\right)}{(2 k+1)(k+1)}+\frac{k^{4}\left(\beta_{i}-\alpha_{i}\right)\left(\beta_{i}+3 \alpha_{i}\right)}{[(2 k+1)(k+1)]^{2}}\right\} \\
& +\sum_{i<j=1}^{n} x_{i} x_{j}\left\{\frac{\left(b_{i}-a_{i}\right)\left(b_{j}-a_{j}\right)}{2}+\frac{k^{2}\left[\left(b_{i}-a_{i}\right)\left(\alpha_{j}+\beta_{j}\right)+\left(b_{j}-a_{j}\right)\left(\alpha_{i}+\beta_{i}\right)\right]}{(2 k+1)(k+1)}+\frac{2 k^{2} \alpha_{i}^{2}}{(k+2)(k+1)}\right. \\
& \left.+\frac{2 k^{4}\left[\left(\beta_{i}-\alpha_{i}\right)\left(\alpha_{j}+\beta_{j}\right)+2 \alpha_{i}\left(\beta_{j}-\alpha_{j}\right)\right]}{[(2 k+1)(k+1)]^{2}}\right\} \\
& +\frac{\left(b_{b}-a_{b}\right)^{2}}{4}+\frac{k^{2} \alpha_{b}^{2}}{(k+1)(k+2)}+\frac{k^{2}\left(b_{b}-a_{b}\right)\left(\beta_{b}+\alpha_{b}\right)}{(2 k+1)(k+1)}+\frac{k^{4}\left(\beta_{b}-\alpha_{b}\right)\left(\beta_{b}+3 \alpha_{b}\right)}{[(2 k+1)(k+1)]^{2}} \\
& +\sum_{i=1}^{n} x_{i}\left\{\frac{\left(b_{i}-a_{i}\right)\left(b_{b}-a_{b}\right)}{2}+\frac{k^{2}\left[\left(b_{i}-a_{i}\right)\left(\alpha_{b}+\beta_{b}\right)+\left(b_{b}-a_{b}\right)\left(\alpha_{i}+\beta_{i}\right)\right]}{(2 k+1)(k+1)}+\frac{2 k^{2} \alpha_{i} \alpha_{b}}{(k+2)(k+1)}\right. \\
& \left.+\frac{2 k^{4}\left[\left(\beta_{i}-\alpha_{i}\right)\left(\alpha_{b}+\beta_{b}\right)+2 \alpha_{i}\left(\beta_{b}-\alpha_{b}\right)\right]}{[(2 k+1)(k+1)]^{2}}\right\} \text {. }
\end{aligned}
$$

In the traditional mean-variance model, the variance is usually used to measure the risk in a portfolio. In fact, it is inappropriate to measure risk using the variance for the following reasons: (1) it only describes the degree of 
deviation of the return, and it does not describe the direction of the deviation; and (2) the variance does not reflect the losses of the portfolio. Therefore, this paper measures the risk using the lower semivariance of the probability of the rate of return on assets and measures the return using the mean probability of the rate of return on assets from the above formulas (11), (12). Assuming that the investor is rational and short-selling is prohibited in the whole investment process, the following model is constructed:

$$
\begin{aligned}
& \min \operatorname{Var}^{-}(\widetilde{R})=\operatorname{Var}^{-}\left(\sum_{i=1}^{n} \widetilde{r}_{i} x_{i}+\widetilde{r}_{b}-C\right), \\
& \text { s.t. } \quad M\left(\sum_{i=1}^{n} \widetilde{r}_{i} x_{i}+\widetilde{r}_{b}\right)-\sum_{i=1}^{n} c_{i}\left|x_{i}-x_{i}^{0}\right| \geq r, \\
& \sum_{i=1}^{n} x_{i}=1, \quad x_{i} \geq 0, i=1,2, \ldots, n,
\end{aligned}
$$

where $r$ represents the minimum level of the investor's net return on the portfolio.

In recent years, according to information entropy theory, many scholars use the proportional entropy as an index to measure the degree of portfolio diversification. The concept of entropy was introduced by the German physicist Rudolph Clausius in 1850 and applied to thermodynamics to express the degree of confusion in the distribution of any kind of energy in space. The more chaotic an energy distribution is, the greater the entropy is. In 1948, Shannon [24] first introduced the concept of entropy into information theory, which is defined as follows.

It is assumed that a random test with $n$ results is performed, and the discrete probability of each result is $p_{i}(i=1,2, \ldots, n)$. The information entropy is

$$
S\left(p_{1}, p_{2}, \ldots, p_{n}\right)=-\sum_{i=1}^{n} p_{i} \ln \left(p_{i}\right),
$$

where $p_{i}(i=1,2, \ldots, n)$ represents the probability of a sample occurrence and it satisfies $\sum_{i=1}^{n} p_{i}=1$.

As a measure of the degree of chaos, entropy has the following properties:

(1) Nonnegative: $S\left(p_{1}, p_{2}, \ldots, p_{n}\right)=-\sum_{i=1}^{n} p_{i} \ln \left(p_{i}\right) \geq 0$

(2) Additivity: for independent events, the sum of entropies is equal to the entropy of sum

(3) Extremum property: when the probability of the occurrence of all samples is equal, that is, $p_{i}=(1 / n)(i=1,2, \ldots, n)$, its entropy reaches the maximum, $S\left(p_{1}, p_{2}, \ldots, p_{n}\right) \leq S((1 / n),(1 / n), \ldots$, $(1 / n))=\ln n$

(4) Asperity: $S\left(p_{1}, p_{2}, \ldots, p_{n}\right)$ is a symmetric concave function for all variables

From the above properties, it is not difficult to find that the information entropy measures the uncertainty of the information. When the information entropy is larger, the uncertainty of the information is greater, and the utility value is smaller. In contrast, the smaller the information entropy is, the smaller the uncertainty of the information is, and the greater the utility value is.
In the investment portfolio research, many researchers use the information entropy to measure the degree of risk diversification in the portfolio, replace the probability of the sample appearance with the investment proportion of the assets in the portfolio, and obtain the measurement index of the degree of decentralization. The proportional entropy can be expressed as

$$
E_{n}(x)=-\sum_{i=1}^{n} x_{i} \ln x_{i}
$$

where $x_{i}$ represents the investment proportion of asset $i(i=1,2, \ldots n)$. From equation (16), when $x_{i}=1 / n$, the value is the maximum; that is, the degree of decentralization of the portfolio of assets is the largest. In real life, however, investors will not allocate wealth to each asset in equal proportions, which does not meet the investors' investment behaviour and when the rate of return $\widetilde{r}_{i}$ of the assets is lower than the rate of return $r_{f}$ of the risk-free assets, that is, $\widetilde{r}_{i}<r_{f}(i=1,2, \ldots, n)$; investors are not going to invest in such assets, and their purpose is to reduce risk and increase revenue through the moderate decentralization of their assets. Based on the above analysis, in order to overcome the deficiency of proportional entropy, Zhang et al. [25] construct the probability entropy based on a decentralized measurement index as follows:

$$
\begin{aligned}
S(x)= & -\sum_{i=1}^{n}\left[\frac{x_{i} \theta\left(x_{i}\right)}{2} \ln \left(\varepsilon+\frac{x_{i} \theta\left(x_{i}\right)}{2}\right)\right. \\
& \left.+\left(1-\frac{x_{i} \theta\left(x_{i}\right)}{2}\right) \ln \left(1-\frac{x_{i} \theta\left(x_{i}\right)}{2}\right)\right],
\end{aligned}
$$

where $\varepsilon>0$ is a sufficiently small number, such as $\varepsilon=1.000 e-7 ; \max \left\{E\left(\widetilde{r}_{i}-r_{f}\right), 0\right\} / \operatorname{Var}\left(\widetilde{r}_{i}\right)$ represents the proportion of remuneration fluctuations in asset $i ; \theta\left(x_{i}\right)=$ $\max \left\{E\left(\tilde{r}_{i}-r_{f}\right), 0\right\} / \operatorname{Var}\left(\tilde{r}_{i}\right) /\left\{\sum_{i=1}^{n} \max \left\{E\left(\tilde{r}_{i}-r_{f}\right), 0\right\} / \operatorname{Var}\right.$ $\left.\left(\widetilde{r}_{i}\right)\right\}$ is the compensation factor of the investment proportion of $x_{i} ; E\left(\widetilde{r}_{i}\right)$ and $\operatorname{Var}\left(\widetilde{r}_{i}\right)$ represent the mean probability and variance of the probability of the $i$-th asset, respectively; and $r_{f}$ represents the rate of return on risk-free assets. Based on the probability entropy of the above decentralization measurement index, it can be seen that the greater the proportion of the return fluctuation of asset $i$ is, the greater the proportion of investment in asset $i$ is. It is not difficult to find that when $E\left(\widetilde{r}_{i}\right)<r_{f}$, the investment proportion $x_{i}=0(i=1,2, \ldots, n)$ of asset $i$ is consistent with the investment decisions of investors in practice.

According to the above analysis, this paper considers investors' attitudes towards risk and their investment decisions on assets with background risk, takes the possible lower variance of the return on assets as the risk measure, measures the return on the basis of the mean probability of the return on assets, and uses the probability entropy as an effective tool for measuring the risk of the lower variance of the probability, which is all done to measure the degree of diversification of the asset portfolio. Therefore, the following probability mean-lower semivariance-entropy model with background risk and transaction costs considering the different risk attitudes of investors is established: 


$$
\begin{array}{ll}
\min & \operatorname{Var}^{-}(\widetilde{R})=\operatorname{Var}^{-}\left(\sum_{i=1}^{n} \widetilde{r}_{i} x_{i}+\widetilde{r}_{b}-C\right) \\
\max & S(x)=-\sum_{i=1}^{n}\left[\frac{x_{i} \theta\left(x_{i}\right)}{2} \ln \left(\varepsilon+\frac{x_{i} \theta\left(x_{i}\right)}{2}\right)+\left(1-\frac{x_{i} \theta\left(x_{i}\right)}{2}\right) \ln \left(1-\frac{x_{i} \theta\left(x_{i}\right)}{2}\right)\right] \\
\text { s.t. } & M\left(\sum_{i=1}^{n} \widetilde{r}_{i} x_{i}+\widetilde{r}_{b}\right)-\sum_{i=1}^{n} c_{i}\left|x_{i}-x_{i}^{0}\right| \geq r \\
\sum_{i=1}^{n} x_{i}=1, & x_{i} \geq 0, i=1,2, \ldots, n
\end{array}
$$

where $r$ represents the minimum level of the investor's net return on the portfolio.

In the above two-objective programming problem (19), there is no optimal solution in the strictest sense, and thus, it is usually transformed into a single objective problem by using the simple weighting method of the objective function. The model is as follows:

$$
\begin{aligned}
& \min \quad \lambda \operatorname{Var}^{-}\left(\sum_{i=1}^{n} \widetilde{r}_{i} x_{i}+\widetilde{r}_{b}-C\right)+(1-\lambda) \sum_{i=1}^{n}\left[\frac{x_{i} \theta\left(x_{i}\right)}{2} \ln \left(\varepsilon+\frac{x_{i} \theta\left(x_{i}\right)}{2}\right)+\left(1-\frac{x_{i} \theta\left(x_{i}\right)}{2}\right) \ln \left(1-\frac{x_{i} \theta\left(x_{i}\right)}{2}\right)\right], \\
& \text { s.t. } \quad M\left(\sum_{i=1}^{n} \widetilde{r}_{i} x_{i}+\widetilde{r}_{b}\right)-\sum_{i=1}^{n} c_{i}\left|x_{i}-x_{i}^{0}\right| \geq r \\
& \sum_{i=1}^{n} x_{i}=1, \quad x_{i} \geq 0, i=1,2, \ldots, n
\end{aligned}
$$

where $\lambda \in[0,1]$ represents the preference coefficient of the investor. $\lambda \longrightarrow 0$ indicates that investors pursue diverse asset portfolios and tend to diversify their investment strategies. $\lambda \longrightarrow 1$ indicates that investors dislike diverse asset portfolios.
Considering the conditional constraints of the model (19), the problem (19) is transformed into the following unconstrained optimization problem that is in the form of penalty function:

$$
\min \lambda \operatorname{Var}^{-}\left(\sum_{i=1}^{n} \widetilde{r}_{i} x_{i}+\widetilde{r}_{b}-C\right)+(1-\lambda) \sum_{i=1}^{n}\left[\frac{x_{i} \theta\left(x_{i}\right)}{2} \ln \left(\varepsilon+\frac{x_{i} \theta\left(x_{i}\right)}{2}\right)+\left(1-\frac{x_{i} \theta\left(x_{i}\right)}{2}\right) \ln \left(1-\frac{x_{i} \theta\left(x_{i}\right)}{2}\right)\right]+L p(x)
$$

where $L>0$ is called the penalty factor and it is a preset large enough normal number. $p(x)=\left(\max \left\{0, r-M\left(\widetilde{r}_{i} x_{i}+\widetilde{r}_{b}\right)+\right.\right.$ $\left.\left.\sum_{i=1}^{n} c_{i}\left|x_{i}-x_{i}^{0}\right|\right\}\right)^{2}+\left(\sum_{i=1}^{n} x_{i}-1\right)^{2}$ is called the constraint violation function, and it is easy to see that $p(x) \geq 0$.

\section{Differential Evolution Algorithm}

4.1. The Basic Principle of the Algorithm. The differential evolution algorithm is similar to the genetic algorithm. Different from the genetic algorithm, it does not need to code and decode the feasible solutions. The initial population of the differential evolution algorithm is randomly generated, and the evolutionary population is formed by mutating, crossing, and selecting each individual in the population until the termination condition is satisfied.

The number of objective function variables in the differential evolution algorithm is the dimension $D$ of the algorithm's search space, and NP is the size of the initial intermediate population, which is generally set by scholars according to the actual situation. The evolution operation of the differential evolution algorithm is controlled by the fitness function. The fitness function can be used to evaluate 
the relative value of the individual relative to the whole population, and the fitness function of this article is expressed as

$$
\lambda \operatorname{Var}^{-}\left(\sum_{i=1}^{n} \widetilde{r}_{i} x_{i}+\widetilde{r}_{b}-C\right)+(1-\lambda) \sum_{i=1}^{n}\left[\frac{x_{i} \theta\left(x_{i}\right)}{2} \ln \left(\varepsilon+\frac{x_{i} \theta\left(x_{i}\right)}{2}\right)+\left(1-\frac{x_{i} \theta\left(x_{i}\right)}{2}\right) \ln \left(1-\frac{x_{i} \theta\left(x_{i}\right)}{2}\right)\right]+L p(x) .
$$

The evolution of the differential evolution algorithm [26] is as follows:

(1) Mutation operation. The mutation operation is carried out on the basis of the difference vector between the parent individuals. Let the currently evolved individual be $x_{i}^{t}$, where $i$ is the serial number of the current individual in the population and $t$ is the number of iterations. Randomly select three individuals $x_{r 1}^{t}, x_{r 2}^{t}$, and $x_{r 3}^{t}(r 1 \neq r 2 \neq r 3 \neq i)$ from the current population and add the vector difference $x_{r 2}^{t}-x_{r 3}^{t}$ between two individuals to $x_{r 1}^{t}$ under the action of scaling factor $F$. Then, the individual $v_{i}^{t+1}$ obtained from the mutation can be expressed as

$$
v_{i}^{t+1}=x_{r 1}^{t}+F\left(x_{r 2}^{t}-x_{r 3}^{t}\right)
$$

(2) Cross-operation. The mutated individual $v_{i}^{t+1}$ and the current evolutionary individual $x_{i}^{t}$ of the population intersect in a discrete crossing manner to generate individual $u_{i}^{t+1}$ and the $j$-th component [26] of individual $u_{i}^{t+1}$ is expressed as follows:

$u_{i}^{t+1}= \begin{cases}v_{i j}^{t+1}, & \text { if rand } \leq \mathrm{CR} \text { or } j=\operatorname{rand} i(1, D), \\ x_{i j}^{t}, & \text { otherwise, }\end{cases}$

where rand is the uniformly distributed random numbers over $(0,1)$ and $\operatorname{rand} i(1, D)$ is a randomly selected integer in $\{1,2,3, \ldots D\}$. To ensure that at least one bit of $u_{i}^{t+1}$ is contributed by $v_{i}^{t+1}$ and $\mathrm{CR} \in[0,1]$ is the cross-probability, it is used to control which variables in $u_{i}^{t+1}$ are contributed by $v_{i}^{t+1}$ and $x_{i}^{t}$. It can be seen that, with the increase in the cross-probability CR, the contribution of $v_{i}^{t+1}$ to $u_{i}^{t+1}$ is also increasing. When $\mathrm{CR}=1, u_{i}^{t+1}=v_{i}^{t+1}$.

(3) Selection operation [27]:

$$
x_{i}^{t+1}= \begin{cases}u_{i}^{t+1}, & \text { if } f\left(u_{i}^{t+1}\right)<f\left(x_{i}^{t}\right) \\ x_{i}^{t}, & \text { otherwise. }\end{cases}
$$

The greedy selection strategy is used to select between the parent individual $x_{i}^{t}$ and the experimental individual $u_{i}^{t+1}$, in which $f(x)$ is the fitness function, and the individual with the best fitness is selected. The selection strategy of the differential evolution algorithm is actually an elite reserve strategy.

\subsection{Improvement of the Differential Evolutionary Algorithm}

4.2.1. Normalization. To solve the above model, the differential evolution algorithm first generates the initial intermediate population. That is, it randomly initializes a group of intermediate particles in the feasible solution space and normalizes each intermediate particle to generate the initial population as follows:

$$
x_{i}=\frac{y_{i}}{\sum_{i=1}^{n} y_{i}}
$$

where $\sum_{i=1}^{n} x_{i}=1, i=1,2, \ldots, n$.

4.2.2. Exponential Increment Crossover Operator. The crossprobability is used to control individual $u_{i}^{t+1}$, which is provided by the mutated individual $v_{i}^{t+1}$ and the current individual $x_{i}^{t}$. As the CR increases, the contribution of the mutated individual $v_{i}^{t+1}$ to $u_{i}^{t+1}$ is greater; and when $\mathrm{CR}=1$, $u_{i}^{t+1}=v_{i}^{t+1}$. In this paper, the cross-probability factor with an exponential increase in random iterations is used, and the updated formula [27] is as follows:

$$
\mathrm{CR}=\mathrm{CR}_{\min }+\left(\mathrm{CR}_{\max }-\mathrm{CR}_{\min }\right) * \exp \left(-a *\left(1-\frac{t}{T_{\max }}\right)^{b}\right)
$$

where $a=40, b=4, T_{\max }$ is the maximum number of iterations, $t$ is the current number of iterations, $\mathrm{CR}_{\min }=0.1$, and $\mathrm{CR}_{\max }=0.9$. In this way, it can avoid the cross-factor is a fixed parameter that makes it fall into the local extreme value, and it can well balance the global and local search ability.

4.2.3. New Mutation Operation. If the mutated individual is considered to be composed of only the random individuals, although it is advantageous to maintain the diversity of the population, the global search capability is strong, but the convergence speed is slow; and if the mutated individual only considers the $x_{\text {best }}^{t}$, although the local search capability is strong and the accuracy is high, the algorithm will fall into the local optimum. Combined with the characteristics of these two methods, the effects of a random individual $x_{r 1}^{t}$ and the optimal individual $x_{\text {best }}^{t}$ are simultaneously considered, the vector difference $\left(x_{r 2}^{t}-x_{r 3}^{t}\right)$ of the two individuals is added to $x_{r 1}^{t}$ and $x_{\text {best }}^{t}$ under the action of the 
scaling factor $\mathrm{F}$, and the mutated individual is obtained. The mutation equation [28] selected in this paper is as follows:

$$
\begin{aligned}
v_{i}^{t+1} & =\eta x_{r 1}^{t}+(1-\eta) x_{\text {best }}^{t}+F\left(x_{r 2}^{t}-x_{r 3}^{t}\right), \\
\eta & =\frac{\left(T_{\max }-t\right)}{T_{\max }}, \\
F & =\eta * 0.5+0.5,
\end{aligned}
$$

where $\eta \in[0,1] ; T_{\max }$ is the maximum number of iterations; $t$ is the current number of iterations; and $F \in[0,2]$ is a scaling factor, which is used to control the scaling degree of difference variables. It can be seen that $F$ linearly decreases as $t$ increases. In the search process, $\eta$ gradually decreases from 1 to 0 . That is, the weight of $x_{r 1}^{t}$ to $x_{\text {best }}^{t}$ gradually increases, which makes the population have better diversity in the early stage and can ensure faster convergence speed and better search accuracy in the later stage.

\subsection{Specific Steps of the Algorithm}

Step 1. Set the basic parameters including the population size NP, the contraction factor $F$, the maximum number of iterations $T_{\max }$, the respective upper and lower bounds $\mathrm{CR}_{\max }$ and $\mathrm{CR}_{\min }$ of the cross-probability $a$ and $b$, the penalty factor $L$, and the control error $\varepsilon$.

Step 2. Randomly generate the initial intermediate population for normalization operations and set the evolutionary algebra to $t=1$.

Step 3. Use formula (22) to calculate the fitness value of each individual, and the optimal fitness value and the optimal individual are obtained.

Step 4. Judge whether the termination condition of the penalty function method is reached or the maximum number of iterations $T_{\max }$ is reached. If so, exit the algorithm and output the optimal value; otherwise, the differential evolution algorithm starts to iterate, and the next step is carried out.

Step 5. The mutation operation, cross-operation, and selection operation are performed according to equations (24), (25), and (27)-(30).

Step 6. The evolutionary algebra to $t=t+1$ and return to step 3 .

\section{Empirical Analysis}

The following examples will be used to illustrate the validity of the model. We assume that the return on assets of investors is a trapezoidal fuzzy number. Randomly select 5 stocks from the Shanghai Stock Exchange and estimate the probability distribution of trapezoidal fuzzy number of return on assets by analyzing the historical information of the relevant stocks [23]. The related information is shown in Table 1.

We use the proposed differential evolution (DE) algorithm with random mutation and exponential increments to solve the model. The specific parameters of the algorithm are
TABLE 1: The probability distribution of the rates of return of assets.

\begin{tabular}{lc}
\hline Assets & Trapezoidal fuzzy number \\
\hline Stock 1 & $(0.0449,0.0505,0.0612,0.0679)$ \\
Stock 2 & $(0.0447,0.0502,0.0608,0.0675)$ \\
Stock 3 & $(0.1276,0.1436,0.1739,0.1930)$ \\
Stock 4 & $(0.0466,0.0524,0.0635,0.0705)$ \\
Stock 5 & $(0.0815,0.0917,0.1111,0.1233)$ \\
Asset with background risk & $(0.0400,0.0450,0.0545,0.0605)$ \\
\hline
\end{tabular}

set as follows: a lot of experimental show that the population size $\mathrm{NP}=30$ and the maximum number of iterations $T_{\max }=$ 200 can greatly reduce the running time of the algorithm. In addition, the parameter $\mathrm{CR}_{\min }=0.1, \mathrm{CR}_{\max }=0.9, a=40$, and $b=4$ in literature [27] enable the algorithm to better balance the global and local search capability. Penalty factor $L=10^{8}$ and $\varepsilon>0$ is a sufficiently small number, such as $\varepsilon=1.000 e-7$. All the tests are run in MATLAB 2015a, on an Intel (R) Celeron (R) CPU G3900@2.80 GHz, Windows 7.

To solve this example, it is assumed that the return of the risk-free asset $r_{f}$ is 0.007 , the transaction cost ratio of the stock is 0.003 , and the investors' minimum net return requirement for a portfolio is 0.085 . Then, the above intelligent algorithm is used to solve the above model, and the investment strategy is obtained as follows.

From Tables 2-4, it can be seen that different risk attitudes result in different investment strategies. Investors invest in the five kinds of assets and one kind of background risk asset according to the risk attitude and the above five investment strategies. The investment proportions in these assets are also different under the different investment strategies. When the risk attitude adaptation value $k=0.5$, the proportion of stock 1 in the five investment strategies is the smallest except for the fourth investment strategy, and the proportion of stock 1 in the fourth investment strategy is also very small. It can be seen that, regardless of the investment strategy, investors are very cautious about investing in stock 1 . However, the investment proportions in the five investment strategies for stocks $1,2,4$, and 5 are the largest. When the risk attitude $k=1.0$, among the five investment strategies, stock 3 accounts for the largest investment proportion since investors prefer stock 3 , and stock 1 accounts for the smallest proportion in investment strategies 1,2 , and 4 . When the risk attitude $k=2.0$, the proportion of stock 5 in investment strategies 2 and 4 is the largest, and compared with the other investment strategies, stock 5 is also welcome by investors.

According to Tables 2-4, we can get that, with the increase in the fitness value of risk attitude, that is, investors' attitude towards risk is changed from the aversion to seeking, the lower semivariance is also increased, that is, the risk is increasing, and the corresponding income is also increasing. Figures 2-4 show the effective frontiers of risk averse, risk neutral, and risk-seeking investors when background risk is involved, and Figure 5 shows the comparison diagram of the effective frontiers of investors under the different risk attitudes with background risk. From Figure 5, it can be intuitively seen that risk-averse investors avoid risk, 
TABle 2: Portfolios, returns, and lower semivariances of risk-averse investors.

\begin{tabular}{llllll}
\hline Risk attitude & \multicolumn{5}{c}{ Portfolio strategies } \\
\hline$k=0.5$ & 0.0405 & 0.0155 & 0.0025 & 0.0854 & 0.0969 \\
$x_{1}$ & 0.1287 & 0.0914 & 0.1334 & 0.0762 & 0.1187 \\
$x_{2}$ & 0.3133 & 0.3501 & 0.3662 & 0.3649 & 0.4062 \\
$x_{3}$ & 0.2048 & 0.2128 & 0.0767 & 0.1789 & 0.1618 \\
$x_{4}$ & 0.3126 & 0.3302 & 0.4212 & 0.2946 & 0.2163 \\
$x_{5}$ & 0.0953 & 0.1129 & 0.1198 & 0.1249 & 0.1260 \\
Return & 0.0040 & 0.0053 & 0.0059 & 0.0063 & 0.0067 \\
Lower semivariance
\end{tabular}

TABle 3: Portfolios, returns, and lower semivariances of riskneutral investors.

\begin{tabular}{llllll}
\hline Risk attitude & \multicolumn{5}{c}{ Portfolio strategies } \\
\hline$k=1.0$ & & & & & \\
$x_{1}$ & 0.0159 & 0.0186 & 0.0893 & 0.0343 & 0.0577 \\
$x_{2}$ & 0.3018 & 0.1446 & 0.0560 & 0.1727 & 0.1087 \\
$x_{3}$ & 0.3689 & 0.3907 & 0.5883 & 0.3916 & 0.4267 \\
$x_{4}$ & 0.0372 & 0.1033 & 0.1900 & 0.1358 & 0.0333 \\
$x_{5}$ & 0.2762 & 0.3428 & 0.0764 & 0.2655 & 0.3735 \\
Return & 0.1011 & 0.1100 & 0.1149 & 0.1267 & 0.1327 \\
Lower semivariance & 0.0144 & 0.0166 & 0.0182 & 0.0211 & 0.0233 \\
\hline
\end{tabular}

TABLE 4: Portfolios, returns, and lower semivariances of ventureseeking investors.

\begin{tabular}{llllll}
\hline Risk attitude & \multicolumn{5}{c}{ Portfolio strategies } \\
\hline$k=2.0$ & 0.1610 & 0.2735 & 0.0042 & 0.0242 & 0.0254 \\
$x_{1}$ & 0.1025 & 0.0116 & 0.2412 & 0.2319 & 0.0096 \\
$x_{2}$ & 0.3431 & 0.3361 & 0.3619 & 0.2709 & 0.4505 \\
$x_{3}$ & 0.1114 & 0.0343 & 0.1438 & 0.1271 & 0.1810 \\
$x_{4}$ & 0.2819 & 0.3446 & 0.2490 & 0.3459 & 0.3335 \\
$x_{5}$ & 0.1219 & 0.1230 & 0.1261 & 0.1321 & 0.1470 \\
Return & 0.0628 & 0.0647 & 0.0673 & 0.0735 & 0.0864 \\
Lower semivariance
\end{tabular}

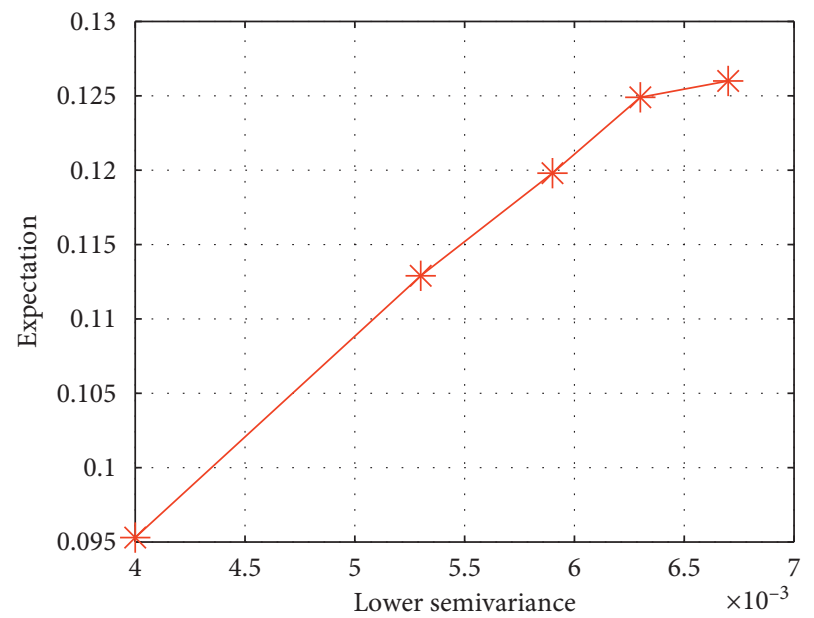

FIgURE 2: The effective frontier of risk-averse investors with background risk.

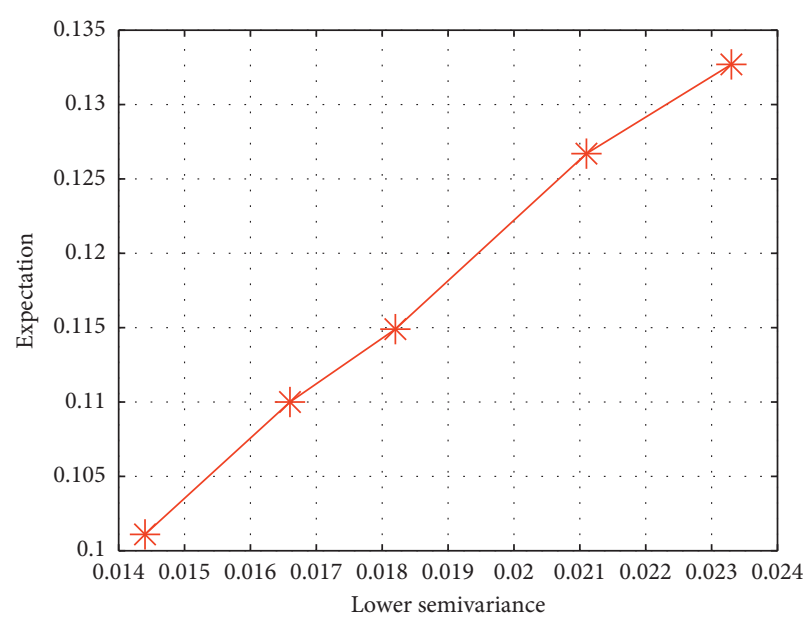

FIGURE 3: The effective frontier of risk-neutral investors with background risk.

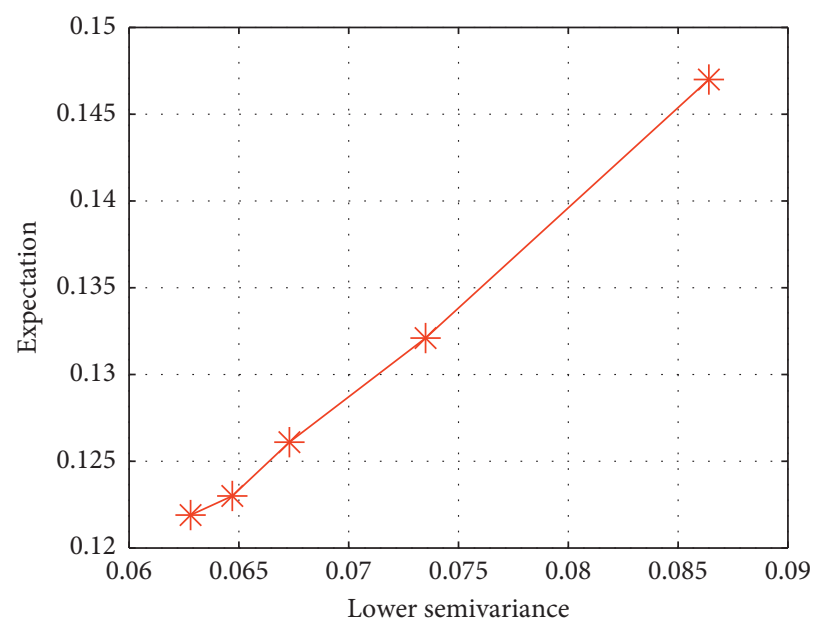

FIGURE 4: The effective frontier of risk-seeking investors with background risk.

and risk-loving investors seek risk because high risk is often accompanied by high returns.

As the risk attitude increases, so does the risk. Investors have different risk attitudes that affect their investment strategy choices. However, by comparing Tables $2-4$, we can find that, under the same risk attitude, the lower semivariance without background risk is much smaller than that with background risk, and the corresponding return is much smaller. Furthermore, the greater the background risk is, the greater the risk that investors will bear, and so the impact of background risk in the investment process cannot be underestimated.

Table 5 shows the returns and lower semivariances of the portfolios without background risk under different risk attitudes. Figures 6-8 show the effective frontiers of risk averse, risk neutral, and risk-seeking investors without background risk under different risk attitudes. Figure 9 compares the effective frontiers of investors under different risk attitudes without background risk. 


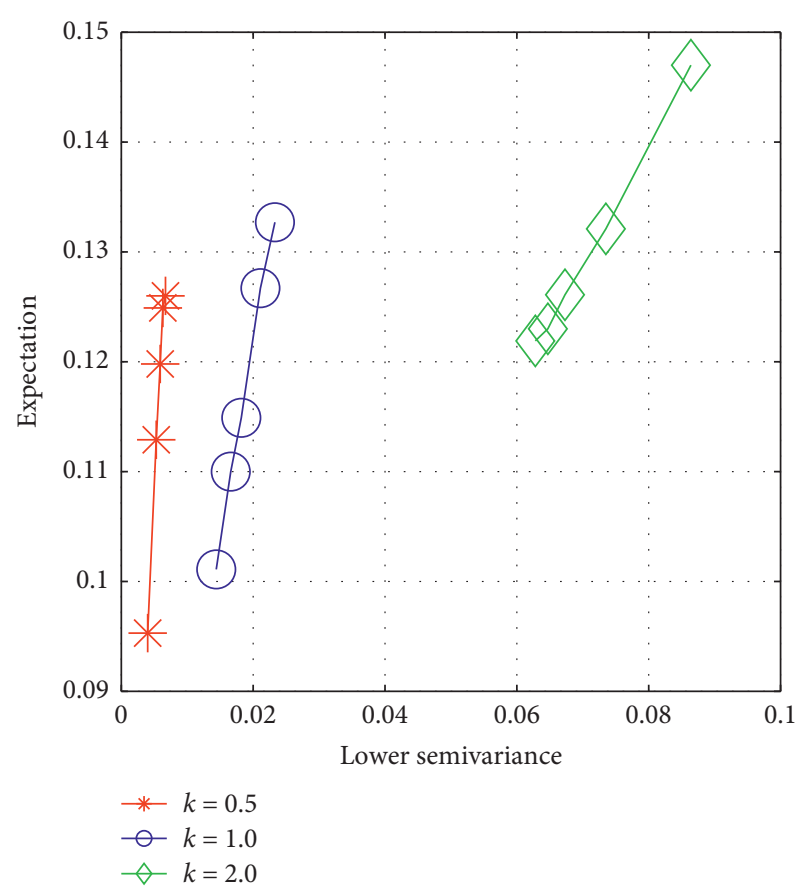

Figure 5: Comparison of effective frontiers of investors under different risk attitudes with background risk.

TABLE 5: Returns and lower semivariances of portfolios without background risk under different risk attitudes.

\begin{tabular}{|c|c|c|c|c|c|}
\hline \multirow{2}{*}{$\begin{array}{l}\text { Risk attitude } \\
k=0.5\end{array}$} & \multicolumn{5}{|c|}{ Portfolio strategies } \\
\hline & & & & & \\
\hline$x_{1}$ & 0.1021 & 0.1458 & 0.3093 & 0.0159 & 0.2609 \\
\hline$x_{2}$ & 0.0208 & 0.0046 & 0.0587 & 0.3018 & 0.0162 \\
\hline$x_{3}$ & 0.5447 & 0.4091 & 0.4348 & 0.3689 & 0.3130 \\
\hline$x_{4}$ & 0.0349 & 0.2421 & 0.0172 & 0.0372 & 0.0347 \\
\hline$x_{5}$ & 0.2974 & 0.1985 & 0.1800 & 0.2762 & 0.3752 \\
\hline Return & 0.0661 & 0.0768 & 0.0825 & 0.0860 & 0.0976 \\
\hline Lower semivariance & 0.0007 & 0.0009 & 0.0010 & 0.0011 & 0.0014 \\
\hline \multicolumn{6}{|l|}{$k=1.0$} \\
\hline$x_{1}$ & 0.0457 & 0.1792 & 0.0042 & 0.0343 & 0.0254 \\
\hline$x_{2}$ & 0.1327 & 0.0276 & 0.2412 & 0.1727 & 0.0096 \\
\hline$x_{3}$ & 0.3489 & 0.4417 & 0.3619 & 0.3916 & 0.4505 \\
\hline$x_{4}$ & 0.2678 & 0.1045 & 0.1438 & 0.1358 & 0.1810 \\
\hline$x_{5}$ & 0.2050 & 0.2469 & 0.2490 & 0.2655 & 0.3335 \\
\hline Return & 0.0701 & 0.0723 & 0.0808 & 0.0832 & 0.1015 \\
\hline Lower semivariance & 0.0017 & 0.0018 & 0.0023 & 0.0024 & 0.0036 \\
\hline \multicolumn{6}{|l|}{$k=2.0$} \\
\hline$x_{1}$ & 0.1717 & 0.0594 & 0.1610 & 0.0242 & 0.0178 \\
\hline$x_{2}$ & 0.0862 & 0.0894 & 0.1025 & 0.2319 & 0.1987 \\
\hline$x_{3}$ & 0.3849 & 0.4446 & 0.3431 & 0.2709 & 0.1669 \\
\hline$x_{4}$ & 0.0204 & 0.0627 & 0.1114 & 0.1271 & 0.0398 \\
\hline$x_{5}$ & 0.3368 & 0.3440 & 0.2819 & 0.3459 & 0.5768 \\
\hline Return & 0.0726 & 0.0777 & 0.0845 & 0.0880 & 0.0954 \\
\hline Lower semivariance & 0.0035 & 0.0040 & 0.0049 & 0.0052 & 0.0060 \\
\hline
\end{tabular}

Figure 10 shows the effective frontier comparison diagram with (without) background risk under different risk attitudes. It can be clearly and intuitively seen that the investment strategy with assets with background risk has high risk, but it is also accompanied by high returns.

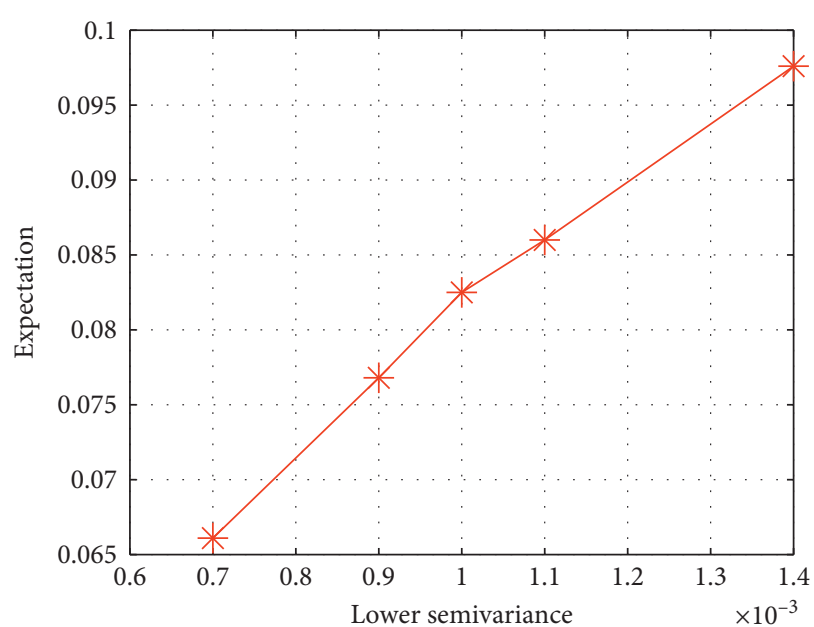

Figure 6: Effective frontier for risk-averse investors without background risk.

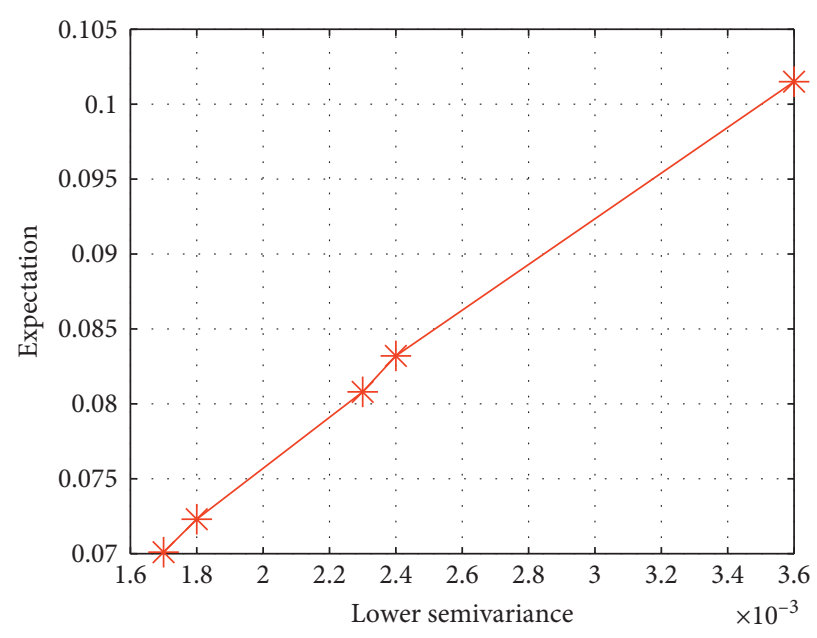

FIGURE 7: Effective frontier for risk-neutral investors without background risk.

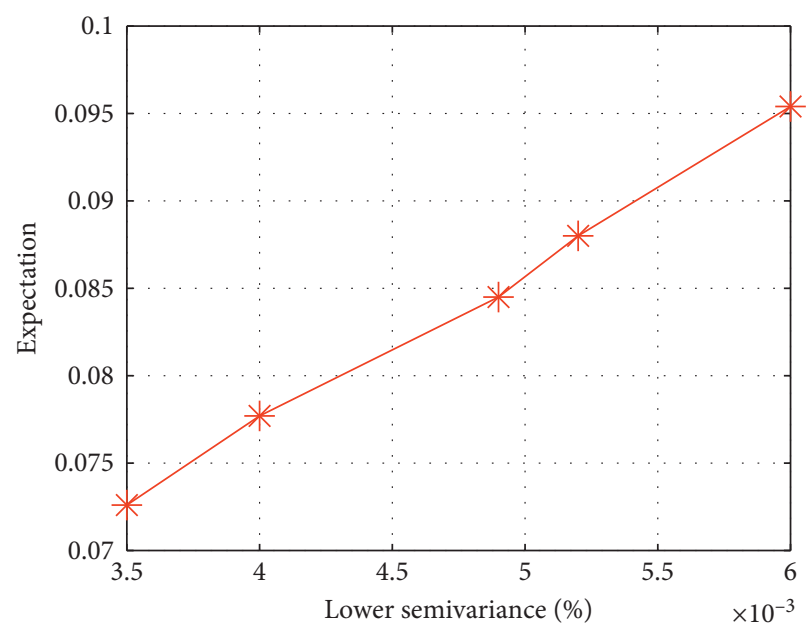

FIGURE 8: Effective frontier for risk-seeking investors without background risk. 


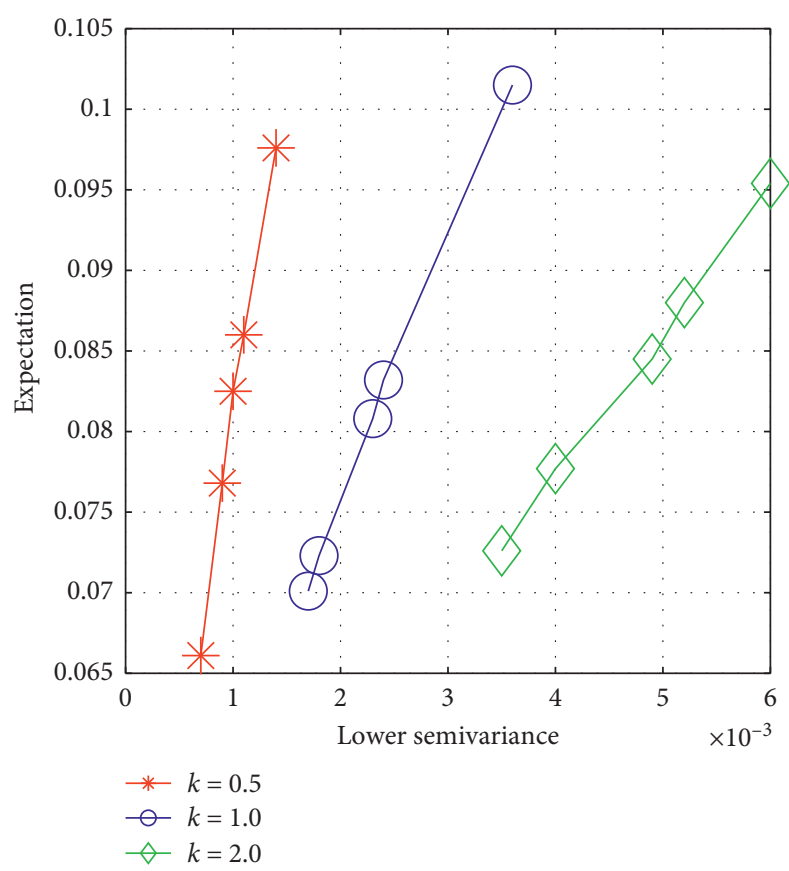

FIGURE 9: Effective frontier comparison of investors under different risk attitudes without background risk.

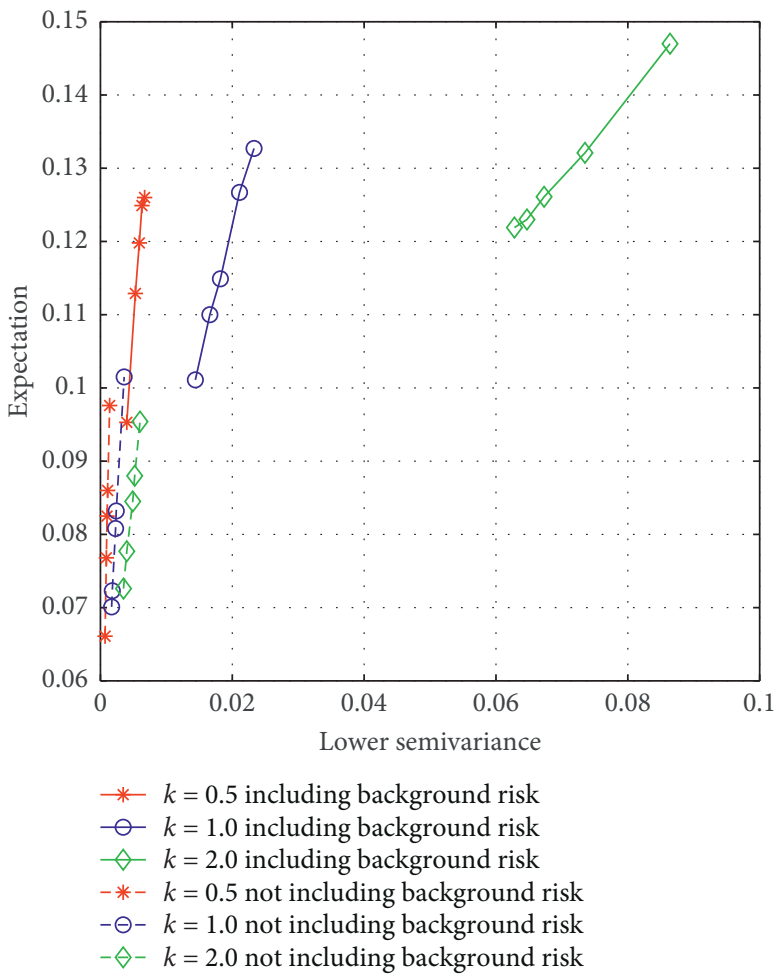

FIGURE 10: Comparison of the effective frontiers with background risks under different risk attitudes.

Table 6 shows the comparison of the returns and the lower semivariances under different risk attitudes. It can be seen that, under the same risk attitude, the lower semivariance of the portfolio without entropy is larger than the lower semivariance of the portfolio with entropy, and the corresponding return is higher than that with entropy. However, when $k=0.5$, the last investment strategy has a lower semivariance of entropy that is larger than the lower 
TABLE 6: Comparison of the entropy factors in portfolios under different risk attitudes.

\begin{tabular}{|c|c|c|c|c|c|c|c|}
\hline & Risk attitude & & & ment po & & & \\
\hline & & Return & 0.0953 & 0.1129 & 0.1198 & 0.1249 & 0.1260 \\
\hline & y-containing & Lower semivariance & 0.0040 & 0.0053 & 0.0059 & 0.0063 & 0.0067 \\
\hline$k=0.5$ & & Return & 0.1148 & 0.1212 & 0.1231 & 0.1257 & 0.1276 \\
\hline & No entropy & Lower semivariance & 0.0055 & 0.0060 & 0.0061 & 0.0065 & 0.0066 \\
\hline & Fntrony-containing & Return & 0.1011 & 0.1100 & 0.1149 & 0.1267 & 0.1327 \\
\hline & Entropy-contaming & Lower semivariance & 0.0144 & 0.0166 & 0.0182 & 0.0211 & 0.0233 \\
\hline$k=$ & & Return & 0.1145 & 0.1178 & 0.1179 & 0.1279 & 0.1283 \\
\hline & No entropy & Lower semivariance & 0.0178 & 0.0186 & 0.0189 & 0.0217 & 0.0224 \\
\hline & & Return & 0.1219 & 0.1230 & 0.1261 & 0.1321 & 0.1470 \\
\hline & Entropy-containing & Lower semivariance & 0.0628 & 0.0647 & 0.0673 & 0.0735 & 0.0864 \\
\hline 2.0 & & Return & 0.1218 & 0.1245 & 0.1287 & 0.1485 & 0.1522 \\
\hline & No entropy & Lower semivariance & 0.0642 & 0.0653 & 0.0698 & 0.0865 & 0.0894 \\
\hline
\end{tabular}

TABle 7: Table of relationship between lambda value and function value under different risk attitudes.

\begin{tabular}{lcc}
\hline Risk attitude & $\lambda$ & Function value \\
\hline \multirow{3}{*}{$k=0.5$} & 0.0868 & -0.5422 \\
& 0.2422 & -0.4125 \\
& 0.5345 & -0.1788 \\
$k=1.0$ & 0.7570 & -0.0959 \\
& 0.0136 & -0.5899 \\
& 0.3168 & -0.2547 \\
& 0.7060 & -0.1051 \\
$k=2.0$ & 0.8816 & -0.0348 \\
& 0.2088 & -0.3090 \\
& 0.4019 & -0.2091 \\
& 0.7975 & -0.0208 \\
& 0.9286 & 0.0300 \\
\hline
\end{tabular}

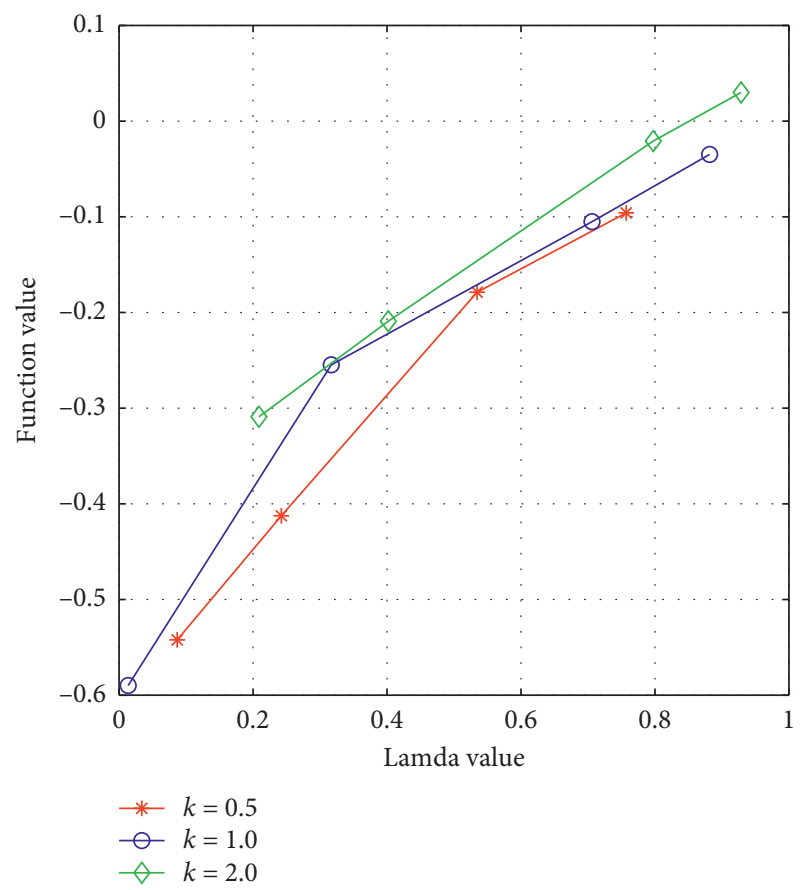

FIgURE 11: $\lambda$ comparison chart under different risk attitudes. semivariance without entropy; when $k=2.0$, the return of the first investment strategy with entropy is also larger than that without entropy. Since the entropy is used to measure the degree of decentralization of the portfolio and reduce the risk, the entropy portfolio has a smaller risk.

For unconstrained optimization problem of the weight of $\lambda$ values as shown in Table 7 , we have done a lot of experiments, respectively, to get $\lambda$ value and function value under different risk attitudes; it can be seen as the $\lambda$ value increases, the function value will increase, under the condition of risk attitude to adapt to the same value, when $\lambda \longrightarrow 0$, probability entropy contribution to the risk control; when $\lambda \longrightarrow 1$, the risk of the lower semivariance measure of probability dominates.

Figure 11 more intuitively shows the changing trend of weighting with different values. When $\lambda \longrightarrow 0$, investors pursue diversified investment strategies and invest more boldly. When $\lambda \longrightarrow 1$, investors hate the diversity of portfolios and invest more cautiously, which is also consistent with the law of risk attitude.

\section{Conclusions}

In the financial market, investors have different perceptions of risk and different attitudes towards risk in the investment process. In this paper, the fuzzy portfolio problem under different risk attitudes is studied. We use the probability mean of the return on assets to measure the return and the lower semivariance to measure the risk. In addition, considering the different attitudes of investors to risk, background risk, and transaction costs, the probability entropy is used as an effective measure for the degree of diversification of an asset portfolio, and a probability mean-lower semivariance-entropy model is constructed. We use a differential evolution algorithm to solve the model and obtain five portfolio strategies under different risk attitudes. The effects of the risk attitude, background risk, and probability entropy on investors' investment decisions are analyzed. Through the experimental results, it is found that the risk-averse investors avoid the risk, and the investors who like the risk seek the risk. Furthermore, the investment in assets with background 
risk will increase the total risk of the investors because the diversification effect of the entropy on the risk can make investors reduce the risks and improve the returns.

\section{Data Availability}

Five stocks are randomly selected from the Shanghai Stock Exchange, and the probability distribution of trapezoidal fuzzy number of return on assets is estimated by analyzing the historical information of the relevant stocks. The data in Table 1 are selected from [23, 27]. All data and models generated or used during the study are available within the article.

\section{Conflicts of Interest}

The authors declare that they have no conflicts of interest.

\section{Acknowledgments}

This research was supported by the National Natural Science Foundation of China under Grant nos. 11961001 and 61561001, the Construction Project of First-Class Subjects in Ningxia Higher Education (NXYLXK2017B09), and the major proprietary funded project of North Minzu University (ZDZX201901).

\section{References}

[1] H. Markowitz, "Portfolio selection," The Journal of Finance, vol. 7, no. 1, pp. 77-91, 1952.

[2] J.-R. Yu and W.-Y. Lee, "Portfolio rebalancing model using multiple criteria," European Journal of Operational Research, vol. 209, no. 2, pp. 166-175, 2011.

[3] Y. Shen, X. Zhang, and T. K. Siu, "Mean-variance portfolio selection under a constant elasticity of variance model," Operations Research Letters, vol. 42, no. 5, pp. 337-342, 2014.

[4] A. O. Petters and X. Dong, Capital Market Theory and Portfolio Risk Measures. An Introduction to Mathematical Finance with Applications, Springer, New York, NY, USA, 2016.

[5] Z. Kang and Z. Li, "An exact solution to a robust portfolio choice problem with multiple risk measures under ambiguous distribution," Mathematical Methods of Operations Research, vol. 87, no. 2, pp. 169-195, 2018.

[6] H. Ma, M. Wu, and N. Huang, "A random parameter model for continuous-time mean-variance asset-liability management," Mathematical Problems in Engineering, vol. 2015, no. 16, Article ID 687428, 2015.

[7] Z. L. Yang, H. Garg, J. Li, G. Srivastavad, and Z. Cao, "Investigation of multiple heterogeneous relationships using a q-rung orthopair fuzzy multi-criteria decision algorithm," Neural Computing and Applications, pp. 1-16, 2020.

[8] W. F. Shape, "Capital asset prices: a theory of market equilibrium under conditions of risk," The Journal of Finance, vol. 19, no. 3, pp. 425-442, 1964.

[9] Z. Qin, "Mean-variance model for portfolio optimization problem in the simultaneous presence of random and uncertain returns," European Journal of Operational Research, vol. 245, no. 2, pp. 480-488, 2015.

[10] M. Zhang and P. Chen, "Mean-variance portfolio selection with regime switching under shorting prohibition," Operations Research Letters, vol. 44, no. 5, pp. 658-662, 2016.
[11] R. Bellman and L. A. Zadeh, "Decision making in a fuzzy environment," Management Science, vol. 17, no. 4, pp. 141-164, 1970.

[12] Y. Fang, L. Bo, D. Zhao, and S. Wang, "Fuzzy views on blacklitterman portfolio selection model," Journal of Systems Science and Complexity, vol. 31, no. 4, pp. 975-987, 2018.

[13] R.-C. Tsaur, "Fuzzy portfolio model with different investor risk attitudes," European Journal of Operational Research, vol. 227, no. 2, pp. 385-390, 2013.

[14] Z. Yang, T. Ouyang, X. Fu, and X. Peng, "A decision-making algorithm for online shopping using deep-learning-based opinion pairs mining and q-rung orthopair fuzzy interaction Heronian mean operators," International Journal of Intelligent Systems, vol. 35, no. 5, pp. 783-825, 2020.

[15] Z. Yang, X. Li, H. Garg, and M. Qi, "Decision support algorithm for selecting an antivirus mask over COVID-19 pandemic under spherical normal fuzzy environment," International Journal of Environmental Research and Public Health, vol. 17, no. 10, p. 3407, 2020.

[16] X. Huang, "An entropy method for diversified fuzzy portfolio selection," International Journal of Fuzzy Systems, vol. 14, no. 1, pp. 160-165, 2012.

[17] N. Lassance and F. D. Vrins, "Minimum Rényi entropy portfolios," 2018, https://arxiv.org/abs/1705.05666.

[18] S. C. Fang, J. R. Rajasekera, and H. S. J. Tsao, Entropy Optimization and Mathematical Programming, Springer Science \& Business Media, Berlin, Germany, 2012.

[19] M. Lee, R. H. Kwon, C.-G. Lee, and H. Anis, "Decentralized strategic asset allocation with global constraints," Journal of Asset Management, vol. 19, no. 1, pp. 13-26, 2018.

[20] Y. Li, B. Wang, A. Fu et al., "Fuzzy portfolio optimization for time-inconsistent investors: a multi-objective dynamic approach," Soft Computing, vol. 24, no. 13, pp. 9927-9941, 2019.

[21] Z. Tao, L. Huiling, W. Wenwen, and Y. Xia, "GA-SVM based feature selection and parameter optimization in hospitalization expense modeling," Applied Soft Computing, vol. 75, no. 2, pp. 323-332, 2019.

[22] Z. L. Yang and J. P. Chang, "Interval-valued pythagorean normal fuzzy information aggregation operators for multiattribute decision making," IEEE Access, vol. 8, pp. 5129551314, 2020.

[23] J. Li, Research on Portfolio Model with Background Risk under Various Measures, Institutes of Technology of South China, Guangzhou, China, 2017.

[24] C. E. Shannon, "A mathematical theory of communication," Bell System Technical Journal, vol. 27, no. 3, pp. 379-423, 1948.

[25] W.-G. Zhang, Y.-J. Liu, and W.-J. Xu, "A possibilistic meansemivariance-entropy model for multi-period portfolio selection with transaction costs," European Journal of Operational Research, vol. 222, no. 2, pp. 341-349, 2012.

[26] J. M. Liu and Y. L. Gao, "Differential evolutionary algorithm with adaptive mutation and exponential incremental crossing operator," Journal of Henan Normal University, vol. 37, no. 6, pp. 18-21, 2009.

[27] Z. X. Deng, D. Q. Cao, X. J. Liu et al., "A new differential evolutionary algorithm," Computer Engineering and Application, vol. 44, no. 24, pp. 40-42, 2008.

[28] H. L. Wu, Y. N. Wang, and Z. L. Chen, "An improved differential evolutionary algorithm for solving mixed integer nonlinear programming problems," Small-scale Micro-computer System, vol. 28, no. 4, pp. 666-669, 2007. 